\title{
Defect density in multiwalled carbon nanotubes influences ovalbumin adsorption and promotes macrophage activation and $\mathrm{CD} 4^{+} \mathrm{T}$-cell proliferation
}

This article was published in the following Dove Press journal:

International Journal of Nanomedicine

2 September 2016

Number of times this article has been viewed

Wei Bai'

Achyut Raghavendra ${ }^{2}$

Ramakrishna Podila ${ }^{2, *}$

Jared M Brown ${ }^{1, *}$

'Department of Pharmaceutical Sciences, Skaggs School of Pharmacy and Pharmaceutical Sciences, University of Colorado-Anschutz Medical Campus, Aurora, CO, ${ }^{2}$ Laboratory of Nano-Biophysics, Department of Physics and

Astronomy, Clemson Nanomaterials

Center and COMSET, Clemson

University, Clemson, SC, USA

*These authors contributed equally to this manuscript
Correspondence: Jared M Brown Department of Pharmaceutical Sciences, Skaggs School of Pharmacy and Pharmaceutical Science, University of Colorado-Anschutz Medical Campus, Mail Stop C238, Aurora, CO 80045, USA $\mathrm{Tel}+\mathrm{I} 3037248213$

Fax +I 3037247266

Email jared.brown@ucdenver.edu
Abstract: Carbon nanotubes (CNTs) are of great interest for the development of drugs and vaccines due to their unique physicochemical properties. The high surface area to volume ratio and delocalized pi-electron cloud of CNTs promote binding of proteins to the surface forming a protein corona. This unique feature of CNTs has been recognized for potential delivery of antigens for strong and long-lasting antigen-specific immune responses. Based on an earlier study that demonstrated increased protein binding, we propose that carboxylated multiwalled CNTs (MWCNTs) can function as an improved carrier to deliver antigens such as ovalbumin (OVA). To test this hypothesis, we coated carboxylated MWCNTs with OVA and measured uptake and activation of antigen-presenting cells (macrophages) and their ability to stimulate $\mathrm{CD}^{+}$ T-cell proliferation. We employed two types of carboxylated MWCNTs with different surface areas and defects (MWCNT-2 and MWCNT-30). MWCNT-2 and MWCNT-30 have surface areas of $\sim 215 \mathrm{~m}^{2} / \mathrm{g}$ and $94 \mathrm{~m}^{2} / \mathrm{g}$, respectively. The ratios of D- to G-band areas $\left(I_{\mathrm{D}} / I_{\mathrm{G}}\right)$ were 0.97 and 1.37 for MWCNT-2 and MWCNT-30, respectively, samples showing that MWCNT-30 contained more defects. The increase in defects in MWCNT-30 led to increased binding of OVA as compared to MWCNT-2 $(1,066 \pm 182 \mu \mathrm{g} / \mathrm{mL}$ vs $582 \pm 41 \mu \mathrm{g} / \mathrm{mL}$, respectively). Both types of MWCNTs, along with MWCNT-OVA complexes, showed no observable toxicity to bone-marrow-derived macrophages up to 5 days. Surprisingly, we found that MWCNT-OVA complex significantly increased the expression of major histocompatibility complex class II on macrophages and production of pro-inflammatory cytokines (tumor necrosis factor- $\alpha$ and interleukin 6), while MWCNTs without OVA protein corona did not. The coculture of MWCNTOVA-complex-treated macrophages and OVA-specific CD4 ${ }^{+}$T-cells isolated from OT-II mice demonstrated robust proliferation of $\mathrm{CD}^{+} \mathrm{T}$-cells. This study provides strong evidence for a role for defects in carboxylated MWCNTs and their use in the efficient delivery of antigens for the development of next-generation vaccines.

Keywords: MWCNT, protein corona, nanoparticle, defect, carboxylation, antigen presentation, immune response

\section{Introduction}

Effective immunotherapy requires identification of target antigens, their efficient delivery, and subsequent interaction with the antigen-presenting cells (APCs) and T-cells without eliciting negative regulatory immune suppression or rejection in the host. Recently, a variety of cancer vaccines have been developed and tested in clinical studies, but only a few trials obtained $>5 \%-10 \%$ partial or complete response. This may be attributed to the failure in vaccine formulation, targeted delivery, and consequent activation of the immune system. ${ }^{1,2}$ Alternatively, antigen-coated microparticles 
(eg, 1-10 $\mu \mathrm{m}$ aluminum salts) have been widely used in both human and veterinary vaccines to stimulate immune responses and improve the efficacy of vaccines, but they had only limited success. ${ }^{2,3}$ With the rapid development of nanotechnology, researchers expect to build on the unique physicochemical properties of nanomaterials to provide new alternatives for the development of vaccines. ${ }^{4}$

Among a wide variety of nanomaterials, carbon nanotubes (CNTs) are one of the most promising candidates for drug and antigen delivery due to their unique physicochemical properties such as high surface area to volume ratio and delocalized pi-electron cloud. For example, recent studies have utilized CNTs to successfully deliver peptides, ${ }^{5}$ cancer testis antigen, ${ }^{6}$ and small molecular $\operatorname{drugs} s^{7,8}$ in various in vitro immune cell lines and in vivo animal models. CNTs are inherently hydrophobic and exhibit a strong tendency to aggregate in aqueous media, which limits their use in biomedical application. Accordingly, as-produced CNTs are often modified using wet chemical methods for adding carboxyl and hydroxyl functionalities to improve their suspension stability. Such surface modifications of CNTs are also known for reducing their toxicity and improving their ability to modulate the immune system. ${ }^{9-12}$ In addition, our proteomics studies showed that carboxylated CNTs bound significantly more serum proteins in cell culture media than pristine nanotubes. ${ }^{13}$ Further, carboxylated CNTs have been proposed for use in vaccine delivery due to their ability to bind protein. ${ }^{8}$ In general, it appears that carboxylation of CNTs enhances their biomedical applicability. However, during the process of carboxylation, surface defects (such as Stone-Wales defects, vacancies, open edges, and functional groups) are often introduced into the CNTs, and it is currently unclear how these surface defects will impact CNTs used in biomedical applications such as antigen delivery for vaccines. Therefore, in this study, we investigated two carboxylated multiwalled CNTs (MWCNTs) with different levels of surface defects.

In this study, we investigated the use of carboxylated MWCNTs with two different defect densities as a vaccine delivery vehicle to deliver a specific antigen to stimulate the immune response. Carboxylated MWCNTs were loaded with ovalbumin (OVA) and delivered to bone-marrow-derived macrophages (BMDMs). These macrophages were cocultured with OVA-specific $\mathrm{CD}^{+}{ }^{+}$T-cells isolated from OT-II mice for 5 days. We demonstrated that OVA was abundantly absorbed on MWCNTs in a defect-density-dependent manner and was efficiently delivered into macrophages without observable toxicity, and OVA peptides were presented on major histocompatibility complex class II (MHCII) and subsequently stimulated the robust proliferation of $\mathrm{CD}^{+}$ T-cells after coculture. Our study provides strong evidence for the use of MWCNTs as an antigen delivery system in the development of vaccines.

\section{Materials and methods Preparation and characterization of MWCNT-OVA complex}

Pristine MWCNTs with two different sizes were obtained from Cheap Tubes Inc., including MWCNT-2 (10-20 nm, 0.5-2 $\mu \mathrm{m})$ and MWCNT-30 (10-20 nm, 10-30 $\mu \mathrm{m})$. Pristine MWCNTs were carboxyl functionalized according to the earlier method. ${ }^{14}$ Size and morphology of carboxylated MWCNTs were evaluated by transmission electron microscopy (TEM) using a Hitachi 7600 (Hitachi Ltd., Tokyo, Japan). Diameter and length measurements were performed on $\geq 100$ CNTs. OVA was purchased from Sigma-Aldrich Co. (St Louis, MO, USA) and dissolved in phosphate-buffered saline (PBS) at $1 \mathrm{mg} / \mathrm{mL}$. To generate MWCNT-OVA complex, $200 \mu \mathrm{L}$ of carboxylated MWCNT $(1 \mathrm{mg} / \mathrm{mL}), 500 \mu \mathrm{L}$ of OVA solution ( $1 \mathrm{mg} / \mathrm{mL})$, and $700 \mu \mathrm{L}$ of distilled water were mixed and incubated on a rotator overnight at $4^{\circ} \mathrm{C}$. The mixture was centrifuged $\left(14,000 \mathrm{rpm}, 10\right.$ minutes, $\left.4^{\circ} \mathrm{C}\right)$, and the pellets were washed twice to remove non-adsorbed OVA. After washing, the pellets were resuspended in distilled water at $1 \mathrm{mg} / \mathrm{mL}$. The hydrodynamic size and zeta potential of either MWCNT or MWCNT-OVA complex were determined using a Zetasizer Nano ZS (Malvern Instruments, Malvern, UK). The surface area measurements were performed on a Quantachrome Autosorb iQ Gas Sorption Analyzer using $\mathrm{N}_{2}$ gas. Raman characterization of MWCNTs was performed using a Renishaw InVia microscope coupled to $514.5 \mathrm{~nm} \mathrm{Ar+}$ laser. The carboxyl group on MWCNTs was quantified using an X-ray photoelectron spectroscopy (XPS) on a Kratos Axis Ultra DLD instrument (Kratos Analytical Ltd, Manchester, UK). Both MWCNT samples did not have detectable levels of endotoxin as measured by Limulus assay.

\section{Quantification of OVA bound to MWCNTs}

To quantify the amount of OVA bound to MWCNTs, the mixture used for the formation of MWCNT-OVA complex was centrifuged $\left(14,000 \mathrm{rpm}, 10\right.$ minutes, $\left.4^{\circ} \mathrm{C}\right)$ and the supernatant was collected. The concentration of OVA in the supernatant was determined by Pierce bicinchoninic acid (BCA) protein assay, which was subtracted from the initial concentration of OVA in the original mixture to calculate the amount of OVA bound to MWCNT. The measurement was 
conducted at least three times. In addition, the thermogravimetric analysis (TGA) was carried out on a Thermogravimetric Analyzer (Pyris 1 TGA; PerkinElmer Inc., Waltham, MA, USA) to conform the binding of OVA to MWCNTs.

\section{Photoluminescence spectroscopy}

Photoluminescence (PL) spectroscopy was used to observe the influence of defects on OVA adsorption; both pristine and functionalized MWCNTs were incubated in OVA solution in PBS at different concentrations for $\sim 12$ hours on a rotator. MWCNT-OVA samples were then centrifuged (14,000 rpm, 10 minutes), and the pellets were washed twice to remove non-adsorbed OVA. After washing, the pellets were resuspended in PBS. The amount of OVA adsorbed per milligram of MWCNT was measured in terms of the PL signal of adsorbed OVA.

\section{Animals and cell models Animals}

Male C57BL/6J mice were purchased from Jackson ImmunoResearch Laboratories, Inc. (Jackson Laboratories, Bar Harbor, ME, USA) at 8-10 weeks of age. Breeding colonies of OT-II transgenic mice were also acquired from Jackson ImmunoResearch Laboratories, Inc. and maintained in the animal facility at the University of Colorado-Anschutz Medical Campus. OT-II transgenic mice express the mouse alpha-chain and beta-chain T-cell receptor that pairs with the CD4 ${ }^{+}$co-receptor and is specific for chicken OVA peptides $\left(\mathrm{OVA}_{323-339}\right)$. All animal procedures were performed in accordance with the guidelines of the Association of Laboratory Animal Care and the National Institutes of Health and approved by the University of Colorado Anschutz Medical Campus Institutional Animal Care and Use Committee.

\section{Bone-marrow-derived macrophages}

Male C57BL/6J mice were sacrificed, and the femur bones were collected. Bone marrow cells were flushed aseptically from the dissected femurs using a $25 \mathrm{G}$ needle. The cells were incubated in RPMI 1640 medium supplemented with 10\% fetal bovine serum, $100 \mathrm{U} / \mathrm{mL}$ penicillin, $100 \mu \mathrm{g} / \mathrm{mL}$ streptomycin, $2 \mathrm{mM}$ L-glutamine, $1 \mathrm{mM}$ sodium pyruvate, and $5 \mu \mathrm{M} 2$-mercaptoethanol, which is referred to as the complete medium. In addition, the complete medium was supplemented with $10 \mathrm{ng} / \mathrm{mL}$ recombinant mouse macrophage colonystimulating factor (M-CSF; R\&D Systems, Inc., Minneapolis, $\mathrm{MN}, \mathrm{USA}$ ). The cells were incubated in a humidified incubator at $37^{\circ} \mathrm{C}$ in $5 \% \mathrm{CO}_{2}$. At day 4 , the medium was replaced with complete medium supplemented with $5 \mathrm{ng} / \mathrm{mL}$ M-CSF.
BMDMs were used following 7 days of culture and were found to contain $>80 \%$ macrophages by expression of F4/80 antigen using monoclonal anti-mouse PerCP-Cyanine5.5conjugated F4/80 antibody (eBioscience, Inc).

\section{Enrichment of CD4 ${ }^{+}$T-cells from OT-II mouse spleens}

On the same day, when macrophages were treated with MWCNTs, OT-II transgenic mice were sacrificed and the spleen was collected. Single cell suspension of splenocytes was obtained using a tissue dissociator (Miltenyi Biotec, Inc., Bergisch Gladbach, Germany), and red blood cells were removed from the splenocytes using Mouse Erythrocyte Lysing Kit (R\&D Systems, Inc.). CD4+ T-cells were enriched using mouse $\mathrm{CD}^{+}{ }^{+} \mathrm{T}$-Cell Enrichment Column Kit according to the manufacturer's procedure (R\&D Systems, Inc.).

\section{Cellular uptake}

We employed fluorescent Texas Red-conjugated OVA (TR-OVA) to form MWCNT-TR-OVA complex to confirm the successful delivery of MWCNT-OVA complex into macrophages using enhanced dark field fluorescent imaging microscopy (Cytoviva, Inc. Auburn, AL, USA). Macrophages were treated with $25 \mu \mathrm{g} / \mathrm{mL}$ of either MWCNT or MWCNT-TR-OVA complex in chamber slides using serum-free medium. The use of serum-free Dulbecco's Modified Eagle's Medium is to prevent the binding of additional serum proteins to either MWCNTs or MWCNT-OVA complex. Following 6-hour exposure, macrophages were washed with PBS and fixed with $4 \%$ paraformaldehyde for 10 minutes at room temperature. The nuclei were stained with 4',6-diamidino-2-phenylindole. The cells were imaged using enhanced dark field fluorescent microscopy. The experiments were repeated at least three times.

\section{Cytotoxicity and apoptosis}

To observe whether MWCNTs with or without OVA binding affect cell viability and induce apoptosis, cytotoxicity and early markers of apoptosis in macrophages were examined following treatment. Briefly, macrophages were treated with $25 \mu \mathrm{g} / \mathrm{mL}$ of either MWCNTs or MWCNT-OVA complex for 6 hours and washed and incubated in complete medium supplemented with $5 \mathrm{ng} / \mathrm{mL}$ M-CSF up to 5 days. Cytotoxicity was monitored at several specific time points using 3-(4,5-dimethylthiazol-2-yl)-5-(3-carboxymethoxyphenyl)2-(4-sulfophenyl)-2H-tetrazolium (MTS) assay according to the manufacturer's protocol (Promega Corporation, Fitchburg, WI, USA). In addition, externalization of phospholipid phosphatidylserine, a hallmark in early apoptosis in 
macrophages, was also detected using Cy5 Annexin V staining according to the manufacturer's protocol (eBioscience, Inc). Camptothecin $(50 \mu \mathrm{M})$ was used as a positive control to treat macrophages for 15 hours to induce apoptosis. Staining with Cy5 Annexin V was used in conjunction with propidium iodide. The experiments were repeated three times.

\section{Characterization of macrophage activation} Macrophages were treated with $25 \mu \mathrm{g} / \mathrm{mL}$ of either MWCNTs or MWCNT-OVA complex for 6 hours and washed and incubated up to 5 days in complete medium supplemented with $5 \mathrm{ng} / \mathrm{mL}$ M-CSF. At day 1, day 3, and day 5, the supernatants were collected for the measurement of tumor necrosis factor- $\alpha$ (TNF $\alpha$ ) and interleukin (IL)-6 production using enzyme-linked immunosorbent assay according to the manufacturer's protocol (R\&D Systems, Inc.). For MHCII expression, macrophages were detached using $0.025 \%$ trypsin and resuspended in staining buffer (Thermo Fisher Scientific, Waltham, MA, USA). Rat monoclonal PE/Cy5-conjugated anti-MHCII (PE/Cy5) antibody (Abcam, Cambridge, UK) was used to detect MHCII expression on macrophages using flow cytometry (Accuri ${ }^{\mathrm{TM}}$ C6 Flow Cytometer; BD Biosciences, San Jose, CA, USA). Prior to labeling MHCII molecules, macrophages were pre-incubated with purified anti-mouse CD16/CD32 mAb (BD Pharmingen; BD Biosciences, San Jose, CA, USA) to reduce Fc-receptor-mediated nonspecific binding. OVA was used as a positive control. The experiments were conducted independently on a minimum of three different batches of BMDMs.

\section{$\mathrm{CD}^{+} \mathrm{T}$-cell proliferation assay}

To investigate whether the OVA delivered by MWCNTs has the ability to stimulate $\mathrm{CD}^{+}{ }^{+} \mathrm{T}$-cell proliferation, 5,6carboxyfluorescein diacetate succinimidyl ester (CFSE)labeled $\mathrm{CD}^{+} \mathrm{T}$-cells were cocultured with macrophages loaded with MWCNT-OVA complex for 5 days. Briefly, macrophages were treated with $25 \mu \mathrm{g} / \mathrm{mL}$ of either MWCNTs or MWCNT-OVA complex in the serum-free medium for 6 hours and were washed and cocultured with CD4 ${ }^{+}$T-cells labeled with the fluorescent dye CFSE (Thermo Fisher Scientific) for 5 days in the complete medium supplemented with $5 \mathrm{ng} / \mathrm{mL}$ M-CSF. The ratio of T-cells to macrophages was 2:1. After 5-day coculture, both macrophages and CD4 ${ }^{+}$ T-cells were detached using $0.025 \%$ trypsin and resuspended in the staining buffer. CD4 ${ }^{+} \mathrm{T}$-cells were then immunostained with APC-conjugated mouse anti-CD4 ${ }^{+}$antibody (eBioscience, Inc) to distinguish them from macrophages. Proliferation of CFSE-labeled $\mathrm{CD}^{+}{ }^{+} \mathrm{T}$-cells by CFSE dilution was analyzed using flow cytometry (AccuriтM C6
Flow Cytometer) and FCS Express 4 Software (De Novo Software, Glendale, CA, USA). A minimum of 2,000 CD4 ${ }^{+}$ T-cells (events/counts) were acquired. The experiments were repeated three times.

\section{Statistical analysis}

All graphs and statistical analysis were performed using Prism 6 software (GraphPad Software, Inc., La Jolla, CA, USA). Statistical significance was analyzed by one-way ANOVA with differences between groups assessed using Dunnett's post hoc tests. Differences were considered statistically significant when $P<0.05$.

\section{Results Characterization of MWCNTs}

Figure 1 shows TEM images of two carboxylated MWCNTs in their dry state. The size analysis indicated that the outer diameters of carboxylated MWCNT-2 and MWCNT-30 were $26 \pm 5 \mathrm{~nm}$ and $18 \pm 3 \mathrm{~nm}$, respectively, which are roughly consistent with the manufacturer specifications. The average length of both carboxylated MWCNTs was found to be $\sim 500 \mathrm{~nm}$, which is much shorter than the manufacturer specifications. We surmise that the functionalization process for adding carboxyl groups resulted in the observed reduction in length due to breaking at the defect site. ${ }^{14} \mathrm{We}$ also characterized the MWCNTs before and after functionalization process using TEM (Figure S1) and found that MWCNTs collapsed and became more rugged after functionalization. Our gas sorption measurements showed that the MWCNT-2 and MWCNT-30 samples have surface areas $\sim 215 \mathrm{~m}^{2} / \mathrm{g}$ and $94 \mathrm{~m}^{2} / \mathrm{g}$, respectively. The Raman spectra of MWCNT-2 and MWCNT-30 showed the presence of the so-called disorder or D-band $\left(\sim 1,350 \mathrm{~cm}^{-1}\right)$ along with the characteristic graphitic band or G-band ( $\sim 1,580 \mathrm{~cm}^{-1}$; Figure 2$)$. Both the samples also exhibited at a higher frequency shoulder to the G-band (known as the $\mathrm{D}^{\prime}$ band $\sim 1,620 \mathrm{~cm}^{-1}$ ) suggesting high defect densities in the samples. The ratio of D- to G-band areas $\left(I_{\mathrm{D}} / I_{\mathrm{G}}\right)$ was calculated to be $0.97 \pm 0.1$ and $1.37 \pm 0.2$ for MWCNT-2 and MWCNT-30, respectively. Furthermore, we used XPS to quantify the functional groups and found that MWCNT-30 contains $\sim 11.5 \mathrm{wt} \%$ of $\mathrm{O}$ and $88.5 \mathrm{wt} \%$ carbon, while MWCNT-2 exhibited $7.3 \mathrm{wt} \%$ of $\mathrm{O}$ and $92.7 \mathrm{wt} \%$ of carbon (Table S1). Both Raman spectra and XPS analysis indicated that MWCNT-30 samples contain more defects.

\section{OVA coating altered the hydrodynamic size and zeta potential of MWCNTs}

To understand the ability of MWCNTs to deliver OVA, it is important to quantitatively determine the amount of 

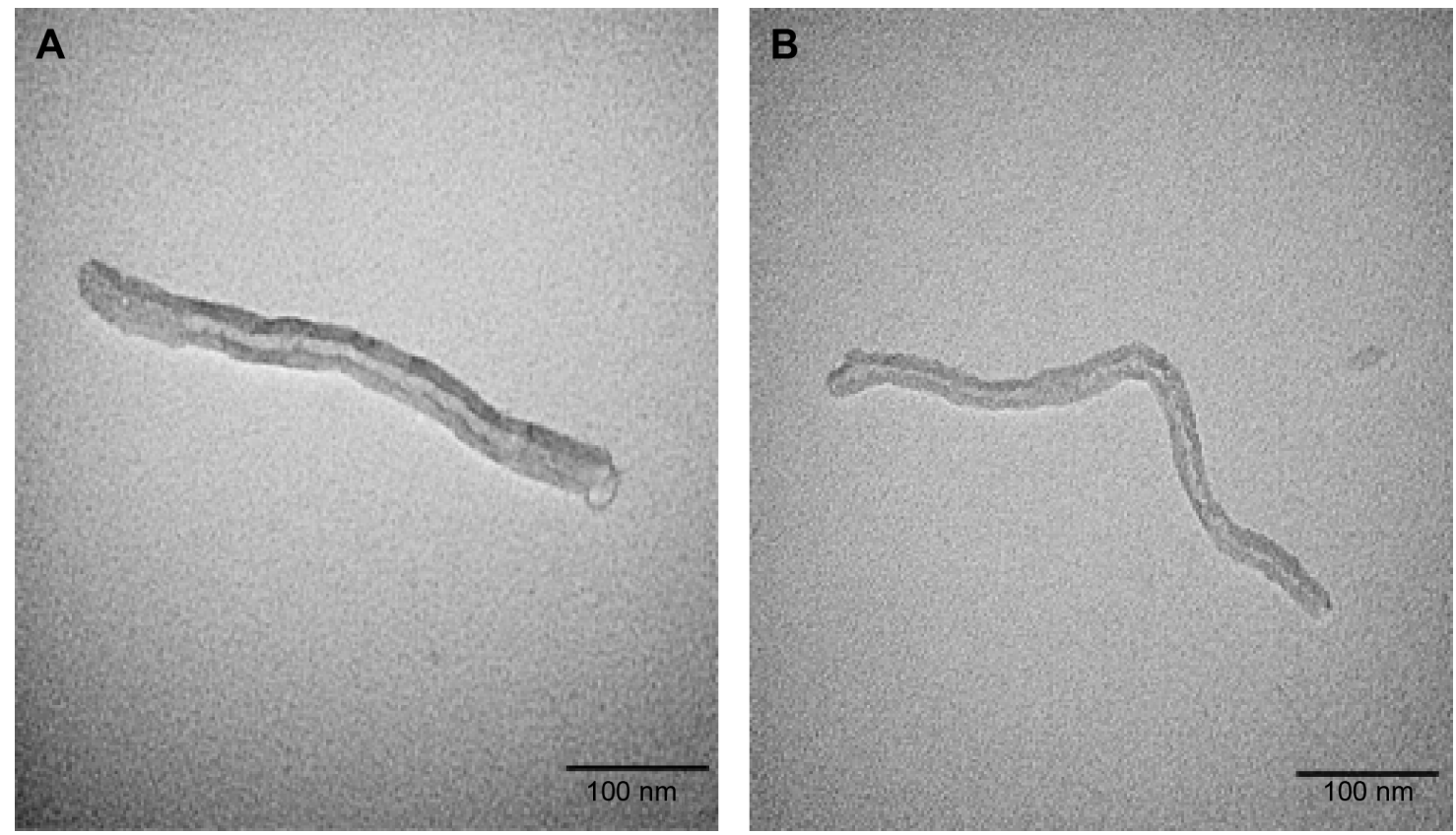

Figure I TEM analysis of carboxylated MWCNT-2 (A) and MWCNT-30 (B).

Notes: The outer diameters of carboxylated MWCNT-2 and MWCNT-30 were $26 \pm 5 \mathrm{~nm}$ and $18 \pm 3 \mathrm{~nm}$, respectively. The average length of both carboxylated MWCNTs was $\sim 500 \mathrm{~nm}$.

Abbreviations: MWCNT, multiwalled carbon nanotube; TEM, transmission electron microscopy.

OVA bound to MWCNTs. Based on BCA protein assay, the amount of OVA bound to MWCNT-2 and MWCNT-30 was $582 \pm 41 \mu \mathrm{g} / \mathrm{mL}(\sim 0.582 \mathrm{mg}$ OVA per $1 \mathrm{~g} \mathrm{CNTs}, 0.271 \mathrm{ng}$ OVA per $\mathrm{cm}^{2}$ of CNTs $)$ and $1,066 \pm 182 \mu \mathrm{g} / \mathrm{mL}(\sim 1.066 \mathrm{mg}$ OVA per $1 \mathrm{~g} \mathrm{CNTs,} 1.12$ ng OVA per $\mathrm{cm}^{2}$ of CNTs), respectively. TGA analysis (Figure S2) showed a marked decrease in the weight percent for CNT-OVA complexes with increasing temperature unlike pristine CNTs confirming the presence of OVA, and the amount of OVA bound to MWCNT-2 and MWCNT-30 was $150 \pm 10 \mu \mathrm{g} / \mathrm{mL}$ and $340 \pm 10 \mu \mathrm{g} / \mathrm{mL}$, respectively. Although TGA results appear to be different from our BCA protein assay, they show the same trend, ie, MWCNT-30 adsorbs almost twice as much OVA. This difference may be rationalized in terms of higher defect density (as seen from Raman spectra in Figure 2) in the case of MWCNT-30 samples. Such an observation is

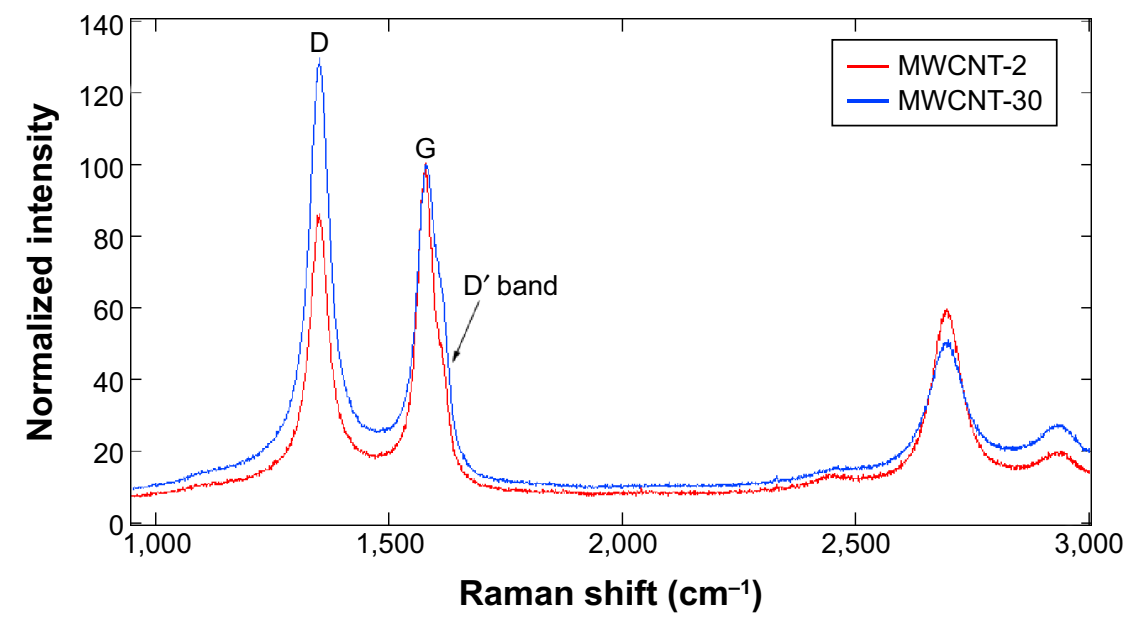

Figure 2 Raman spectra of carboxylated MWCNT-2 and MWCNT-30.

Notes: D-band $\left(\sim 1,350 \mathrm{~cm}^{-1}\right)$ was found along with the characteristic G-band $\left(\sim 1,580 \mathrm{~cm}^{-1}\right)$. Both MWCNTs also exhibited at a higher frequency shoulder to the G-band (known as the $D^{\prime}$ band $\sim 1,620 \mathrm{~cm}^{-1}$ ) suggesting high defect densities in MWCNTs. The ratio of D- to G-band areas $\left(I_{\mathrm{D}} / I_{\mathrm{G}}\right)$ was 0.97 and I.37 for MWCNT-2 and MWCNT-30, respectively, indicating that MWCNT-30 samples contain more defects.

Abbreviation: MWCNT, multiwalled carbon nanotube. 
A

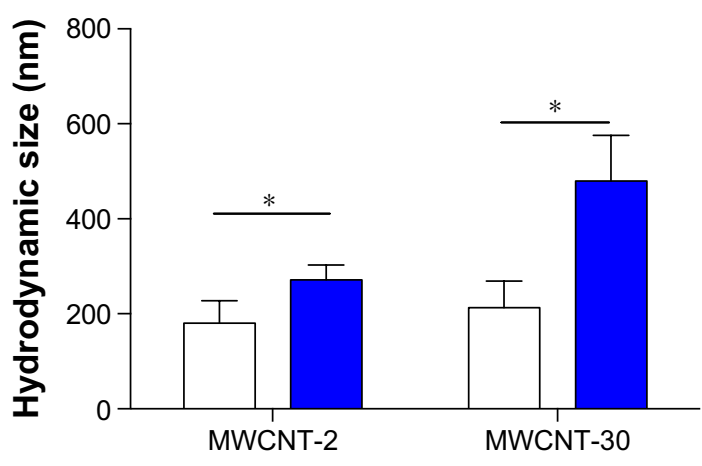

B

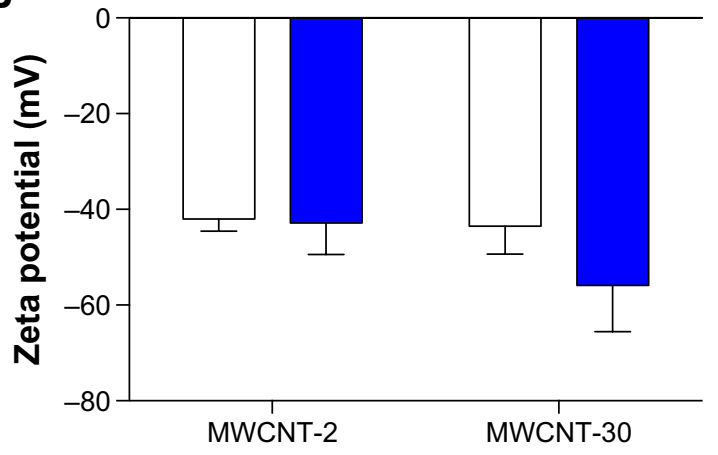

Uncoated OVA coated

Figure 3 Effects of OVA coating on the hydrodynamic size and zeta potential of MWCNTs.

Notes: (A) OVA coating increased the hydrodynamic size of MWCNTs, but had little impact on zeta potential of MWCNTs (B); $n=3$, mean \pm SD, $* P>0.05$ comparison between MWCNTs with and without OVA coating. Results are in response to an analysis of variance test.

Abbreviations: MWCNT, multiwalled carbon nanotube; OVA, ovalbumin.

in agreement with our earlier experimental and theoretical studies, which show that the defects strongly influenced biomolecular adsorption. ${ }^{15}$

TEM characterization showed the length of MWCNTs in a dry state; however, MWCNTs undergo a certain degree of agglomeration upon dispersion. We measured the hydrodynamic size and zeta potential of MWCNTs using dynamic light scattering. Dynamic light scattering measurement showed similar hydrodynamic size ( $200 \mathrm{~nm})$ of MWCNT-2 and MWCNT-30 due to agglomeration (Figure 3A). As expected, MWCNT-OVA complex showed a significant increase in hydrodynamic size than uncoated MWCNTs. OVA coating increased the size of MWCNT-30 to a greater degree than MWCNT-2 (Figure 3A), which was concomitant with the amount of bound OVA. In addition, although both MWCNT-2 and MWCNT-30 have the similar zeta potential (Figure 3B), we found that OVA coating slightly decreased the zeta potential of MWCNT-30 (Figure 3B) but not MWCNT-2 resulting in a more negatively charged MWCNT-30.

\section{Defects exerted an influence on adsorption of OVA on MWCNTs}

We used PL spectroscopy to study the effect of defects on the adsorption of OVA on MWCNTs. The aromatic amino acid content in OVA absorbs light strongly at $\sim 280 \mathrm{~nm}$ and emits at $\sim 338 \mathrm{~nm}$, and a standard curve was established in terms of the intensity of the emission peak $(\sim 338 \mathrm{~nm})$ in OVA (Figure 4A). We observed clear differences between all MWCNT-2 and MWCNT-30 samples in both pristine and functionalized forms (Figure $4 \mathrm{~B}$ and $\mathrm{C}$ ). Indeed, in the case of MWCNT-30, we found that OVA adsorption deviates from a linear trend (as shown by the dashed black line in Figure 4B and C) at higher concentrations. On the other hand, MWCNT-2 exhibited Langmuir-like isotherm (Figure 4B, inset) in both pristine and carboxylated forms. The results indicated that while carboxylated MWCNT-2 and MWCNT-30 showed similar adsorption at lower concentrations, both trends deviated from linearity albeit in different directions (as shown by dashed black line) at higher concentrations.

\section{Evaluation of OVA delivery into macrophages by MWCNTs}

To demonstrate the successful delivery of OVA by MWCNTs into macrophages, we employed dark field microscopy in conjunction with fluorescent TR-OVA to confirm the uptake of MWCNT-TR-OVA complex by macrophages (Figure 5). After 6-hour treatment, macrophages treated with or without MWCNTs alone did not show any fluorescence. In comparison, macrophages treated with OVA showed fluorescence, and most interestingly, macrophages treated with MWCNTTR-OVA complex showed strong fluorescence, suggesting that both MWCNT-2 (Figure 5) and MWCNT-30 (Figure S3) successfully delivered OVA into macrophages.

\section{MWCNT-OVA complex induced classical activation of macrophages}

We found that neither MWCNTs nor MWCNT-OVA complex had an impact on the cell viability of macrophages up to 5 days using MTS assay (Figure 6). We further investigated whether MWCNT-OVA complex activated macrophages. Classically activated macrophages are characterized by the production of pro-inflammatory cytokines, such as TNF $\alpha$ and 

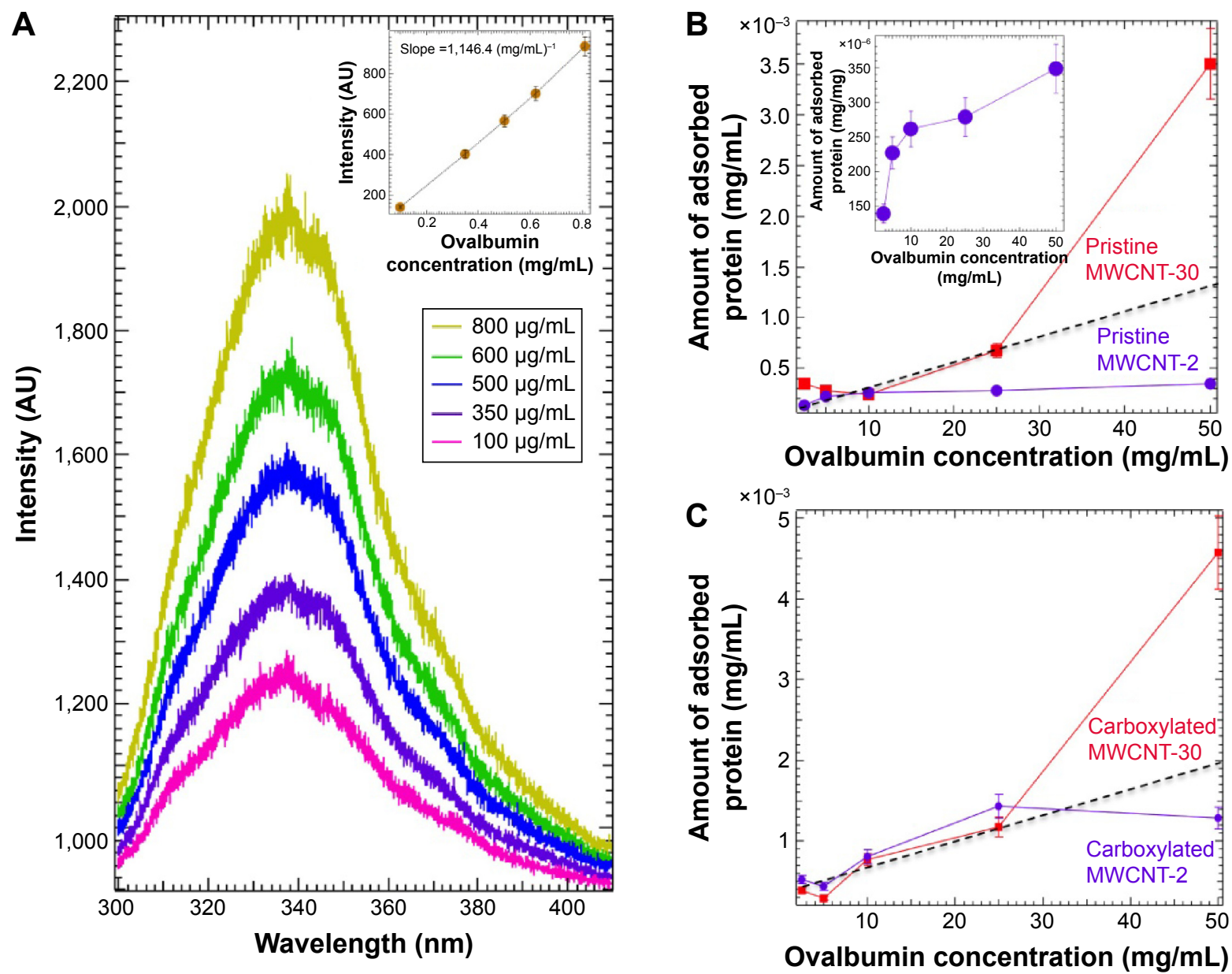

Figure 4 Binding of OVA to MWCNTs confirmed by PL spectroscopy.

Notes: (A) The standard curve in terms of the intensity of the emission peak ( $338 \mathrm{~nm})$, (B) PL spectrum of pristine MWCNT-2 and MWCNT-30, (C) PL spectrum of carboxylated MWCNT-2 and carboxylated MWCNT-30. Data are mean \pm SD.

Abbreviations: MWCNT, multiwalled carbon nanotube; OVA, ovalbumin; PL, photoluminescence.

IL-6, and the expression of MHCII. ${ }^{16} \mathrm{OVA}$ alone remarkably induced the production of both TNF $\alpha$ and IL- 6 up to 5 days after treatment (Figure 7A and B), while MWCNT-2 and MWCNT-30 alone had no effect on the production of TNF $\alpha$ and IL- 6 by macrophages (Figure 7A and B). Interestingly, both MWCNT-2-OVA and MWCNT-30-OVA complexes induced significantly higher production of both $\mathrm{TNF} \alpha$ and IL-6 after treatment compared to OVA treatment alone. Importantly, MWCNT-30-OVA complex induced a greater cytokine production compared to MWCNT-2-OVA complex (Figure 7A and B) due to higher OVA adsorption.

In addition to cytokine production, OVA gradually increased MHCII expression from day 3 to day 5 (Figure 7C). Similarly, both MWCNT-2-OVA complex and MWCNT30-OVA complex dramatically increased MHCII expression on macrophages from day 1 to day 5 (Figure 7C). It is interesting that the MWCNT-OVA complex appears to be able to stimulate MHCII expression more rapidly than OVA alone suggesting that the MWCNTs facilitated enhanced delivery of OVA into macrophages. In contrast, neither MWCNT-2 nor MWCNT-30 alone had impact on the expression of MHCII at day 1 and day 3, but showed an inhibition of MHCII expression on day 5 following exposure (Figure 7C).

\section{MWCNT-OVA complex enhanced CD4 ${ }^{+}$ T-cell proliferation in an APC assay}

As in Figure 7, macrophages were effectively activated by MWCNT-OVA complexes. Therefore, we further investigated whether these activated macrophages in turn enhanced $\mathrm{CD}^{+} \mathrm{T}$-cell proliferation using OVA-specific $\mathrm{CD}^{+} \mathrm{T}$-cells isolated from OT-II mice. We cocultured CFSElabeled OT-II CD4 ${ }^{+}$T-cells with macrophages treated with either MWCNTs or MWCNT-OVA complex. As expected, OVA alone induced $\mathrm{CD}^{+} \mathrm{T}$-cell proliferation (Figure 8A). Interestingly, we found that both MWCNT-2-OVA complex and MWCNT-30-OVA complex significantly induced the 


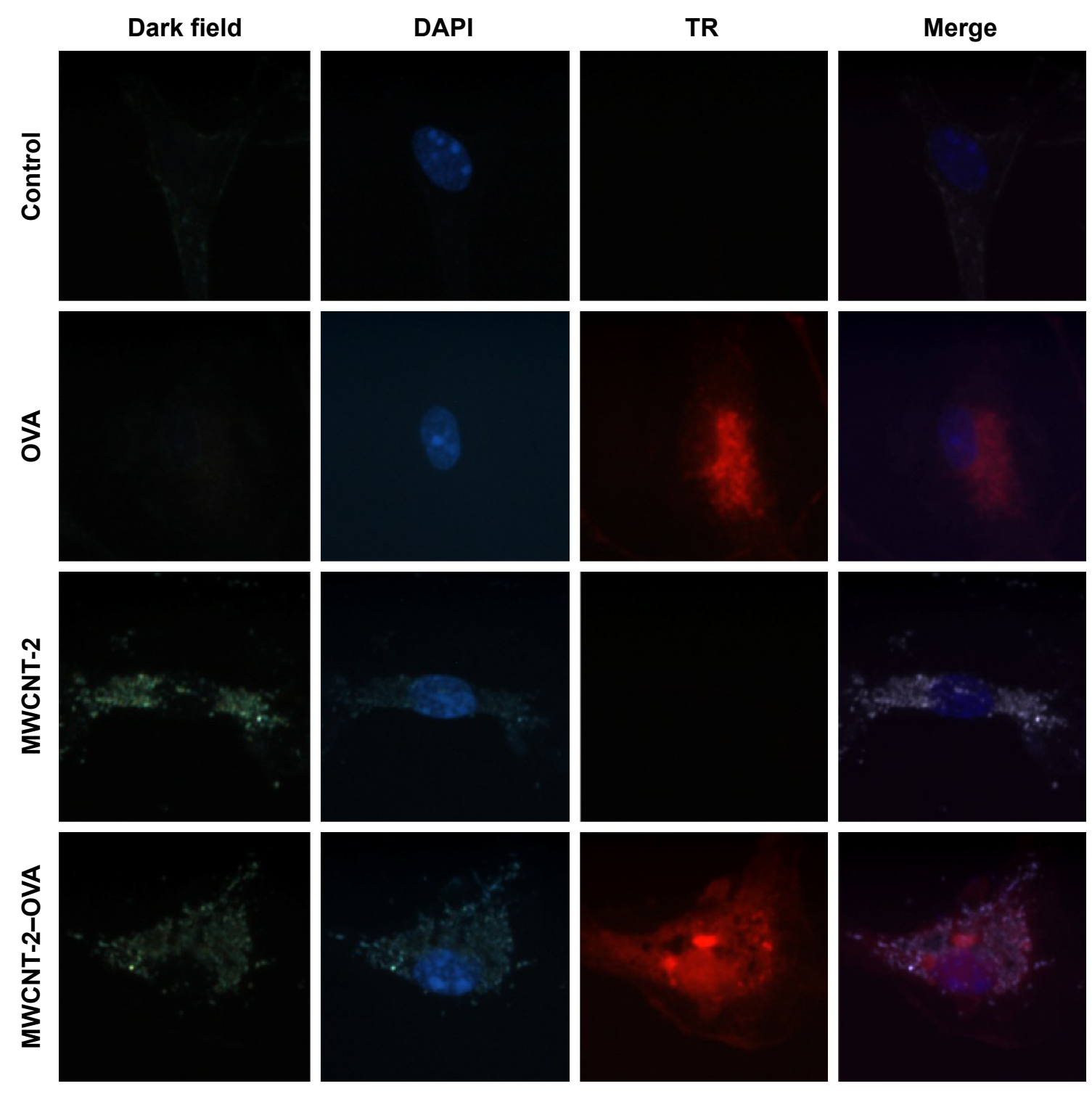

Figure 5 Delivery of fluorescent TR-OVA by MWNCT-2 into BMDMs visualized by dark field and fluorescent microscopy.

Notes: Macrophages treated with or without MWCNTs alone showed no fluorescence, but macrophages treated with OVA and MWCNT-TR-OVA complex showed strong fluorescence (magnification: I00X).

Abbreviations: BMDMs, bone-marrow-derived macrophages; DAPI, 4',6-diamidino-2-phenylindole; MWCNT, multiwalled carbon nanotube; OVA, ovalbumin; TR-OVA, Texas Red-conjugated OVA.

proliferation of $\mathrm{CD}^{+} \mathrm{T}$-cells, but MWCNT alone had no impact on $\mathrm{CD}^{+} \mathrm{T}$-cell proliferation (Figure $8 \mathrm{~B}$ and $\mathrm{C}$ ). We also found that MWCNT-30-OVA complex induced greater $\mathrm{CD}^{+}$T-cell proliferation than MWCNT-2-OVA complex, which was supported by the observation that there were six distinguished generations of $\mathrm{CD}^{+} \mathrm{T}$-cells with MWCNT30-OVA complex, but only four with the others (OVA or MWCNT-2-OVA complex; Figure 8).

\section{Discussion}

The potential applications of CNTs in medicine have been increasingly attracting more research interest mainly because of their unique properties, such as high specific surface area that allows for improved binding and delivery of biological and bioactive molecules. ${ }^{12}$ Carboxylation is one of the most widely used methods to improve the solubility of CNTs in aqueous environments. In this study, we examined carboxylated MWCNTs with different levels of defects for their ability to deliver antigen and stimulate an immune response including macrophage activation and $\mathrm{CD} 4^{+} \mathrm{T}$-cell proliferation.

It is well known that the physicochemical properties of CNTs have dramatic impact on their potential applications in medicine. ${ }^{10,17-19}$ It has been hypothesized that electronically 

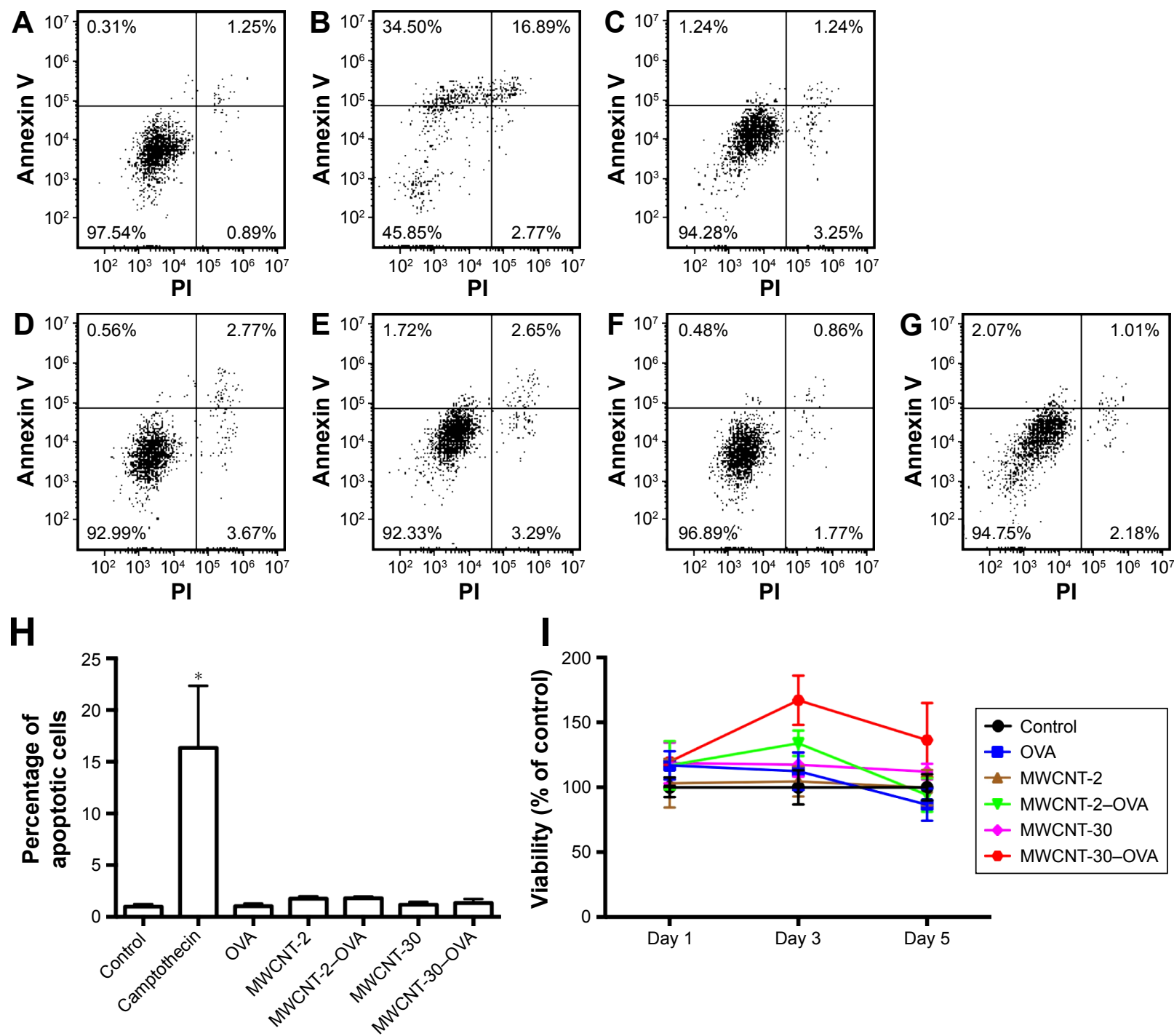

Figure 6 Effects of MWCNTs or MWCNT-OVA complex on cellular viability and apoptosis of BMDMs.

Notes: Flow cytometry analysis of Annexin V and PI staining of apoptotic cells, (A) control, (B) camptothecin, (C) OVA, (D) MWCNT-2, (E) MWCNT-2-OVA complex, (F) MWCNT-30, (G) MWCNT-30-OVA complex, (H) percentage of apoptotic cells (Annexin V positive and PI positive; $n=3$, mean \pm SD). (I) Viability of BMDMs using MTS assay $(n=6$, mean \pm SD). MWCNTs or MWCNT-OVA complex showed no observable effect on cellular viability of macrophages up to 5 days. $* P>0.05$, compared to the control group. Results are in response to an analysis of variance test.

Abbreviations: BMDMs, bone-marrow-derived macrophages; MWCNT, multiwalled carbon nanotube; OVA, ovalbumin; PI, propidium iodide.

active surface defects (ie, lattice imperfections, such as Stone-Wales defects, vacancies, open edges, and functional groups present on the outermost graphitic shell of MWCNTs) can act as charge transfer sites (ie, electron donors or acceptors) to enhance protein binding, produce oxygen species, and disrupt cellular homeostasis. ${ }^{20,21}$ Given that defects in MWCNTs vary from batch to batch and depend strongly on synthesis conditions, we hypothesized that differences in defect density between MWCNT-2 and MWCNT-30 would impact protein binding and subsequent effects on antigenic responses in macrophages. Our earlier study demonstrated that defects in CNTs play an important role in determining nano-bio interactions and can lead to higher protein adsorption (albumin and fibrinogen) due to charge transfer. ${ }^{15}$ In this study, we further found that MWCNT-30 with more defects has a greater capacity to bind OVA as compared to MWCNT-2. Based on such findings, we surmise that the higher defect density in MWCNT-30 compared to MWCNT-2 resulted in higher adsorption (Figure 4B and C) through the stabilization of MWCNTs-30 by OVA. Although this difference in binding of OVA did not impact toxicity between MWCNT-2 and MWCNT-30, this had a large impact on subsequent macrophage activation and $\mathrm{CD} 4^{+}$ T-cell proliferation.

The toxicity associated with CNTs represents a significant barrier to their potential use in biomedical applications. 

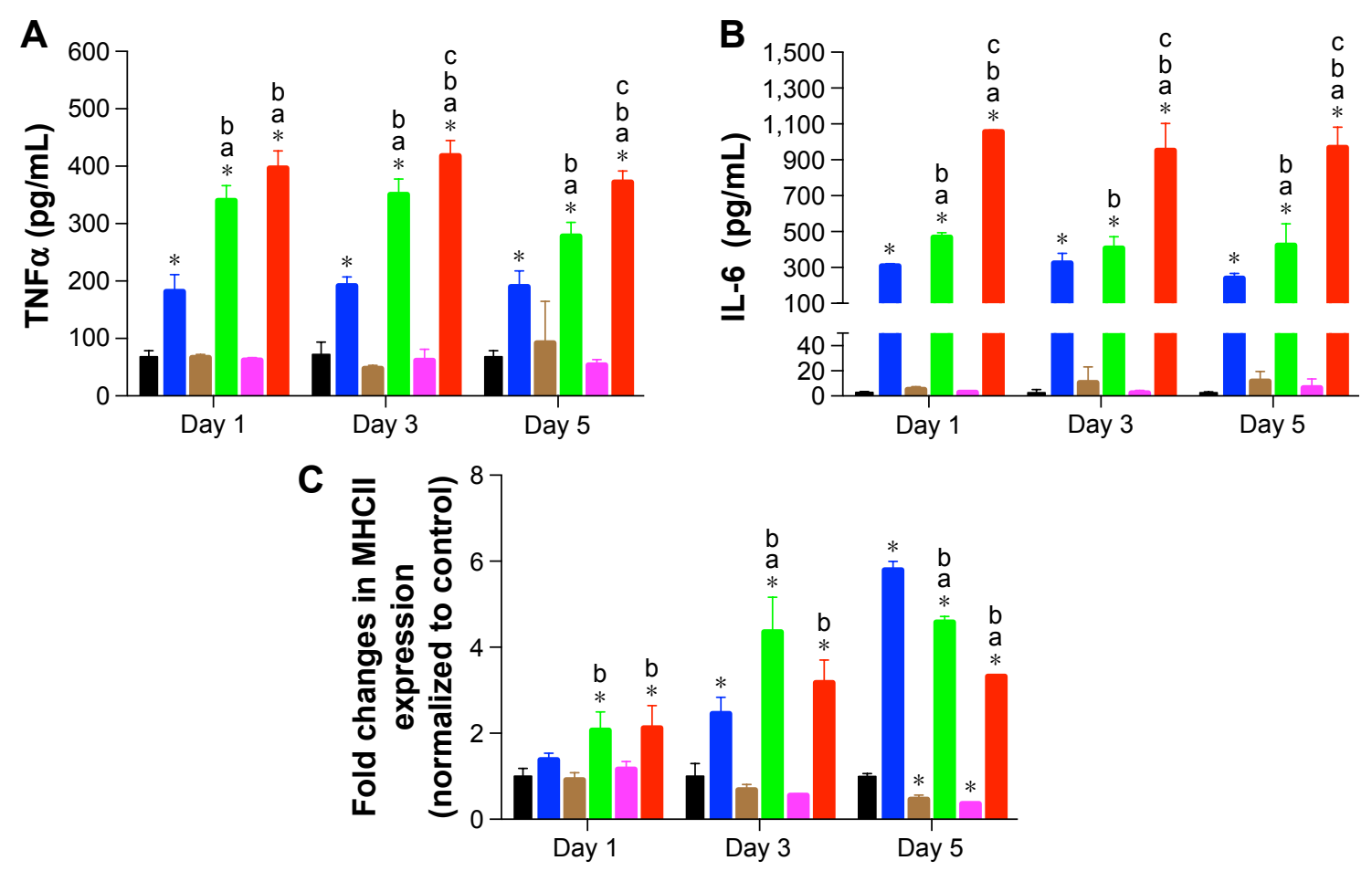

Control OVA MWCNT-2 IMWCNT-2-OVA I MWCNT-30 IWCNT-30-OVA

Figure 7 Activation of macrophages by MWCNT-OVA complex.

Notes: MWCNT-OVA complex induced high production of inflammatory cytokines in macrophages as compared to MWCNT alone, including (A) TNF $\alpha$ and (B) IL-6 $(n=3-6$, mean $\pm S D)$, and MWCNT-OVA complex significantly induced MHCll expression on macrophages (C). $* P>0.05$, compared to the control group; a, $P>0.05$, compared to the OVA-treated group; b, $P>0.05$, compared to unbound MWCNTs; $c, P>0.05$, comparison between MWCNT-2-OVA complex and MWCNT-30-OVA complex. Results are in response to an analysis of variance test.

Abbreviations: IL-6, interleukin 6; MHCII, major histocompatibility complex class II; MWCNT, multiwalled carbon nanotube; OVA, ovalbumin; TNF $\alpha$, tumor necrosis factor- $\alpha$.
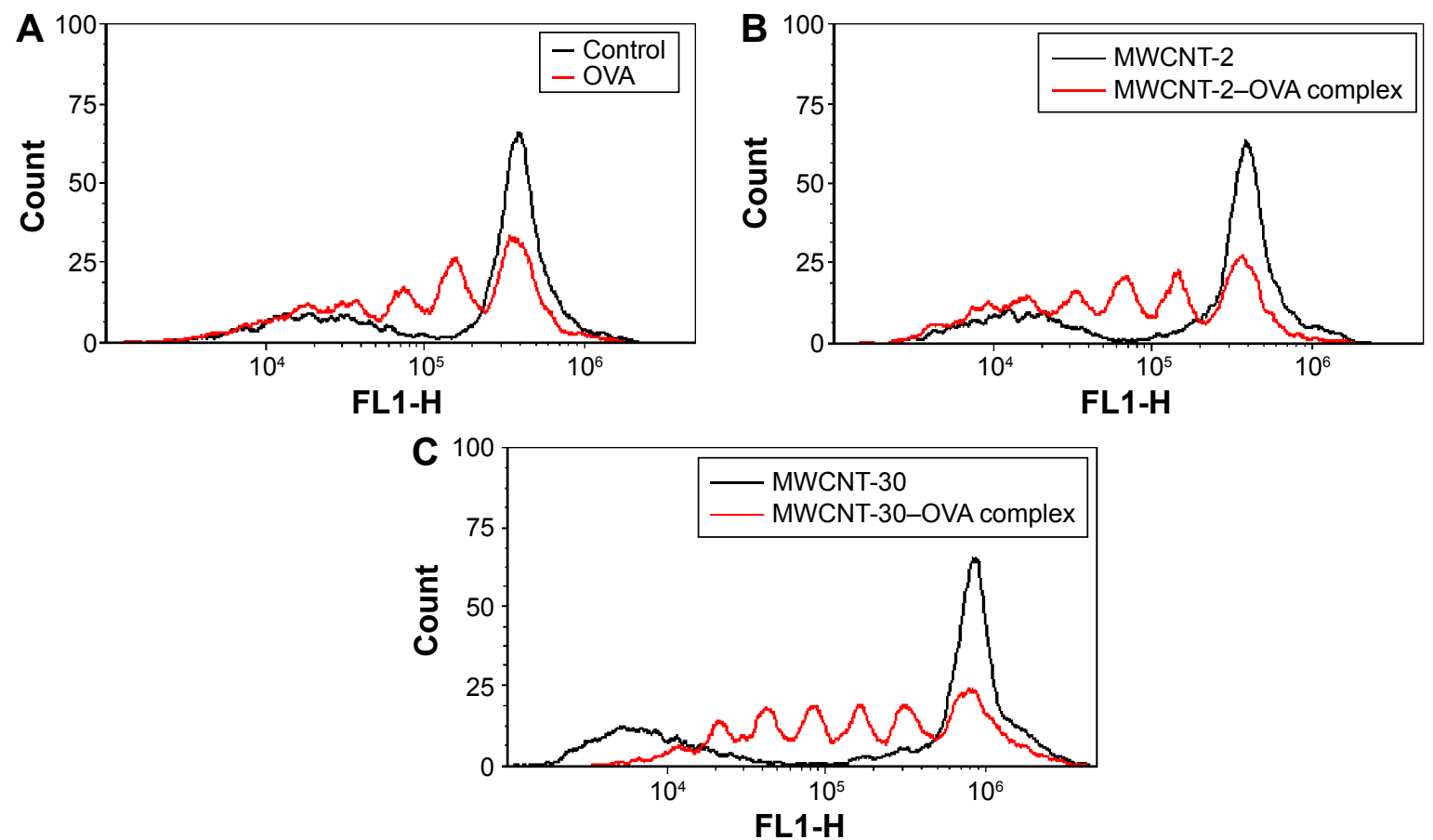

Figure 8 MWCNT-OVA complex remarkably induced CD4 ${ }^{+}$T-cell proliferation.

Notes: (A) Proliferation of OT-II CD4 ${ }^{+}$T-cells after coculture with untreated macrophages (black line) and OVA-treated macrophages (red line), (B) proliferation of OT-II CD4 ${ }^{+}$T-cells after coculture with macrophages treated with MWCNT-2 (black line) and MWCNT-2-OVA complex (red line), and (C) proliferation of OT-II CD4+ T-cells after coculture with macrophages treated with MWCNT-30 (black line) and MWCNT-30-OVA complex (red line). Abbreviations: MWCNT, multiwalled carbon nanotube; OVA, ovalbumin; FLI-H, Fluorescence channel I height. 
Recent studies have suggested that the toxicity of CNTs is dependent on their length, and in general, longer CNTs show increased toxicity to cells. For example, our earlier studies found that MWCNTs with a length of 10-100 $\mu \mathrm{m}$ impaired pulmonary function ${ }^{22}$ and induced severe cardiac ischemic/ reperfusion injury after pulmonary instillation. ${ }^{23}$ Similar results on MWCNT toxicity were also reported elsewhere, ${ }^{24-27}$ such as subchronic toxicity, asbestos-like pathogenicity in mice, and airway fibrosis. In contrast, CNTs with a length shorter than $2 \mu \mathrm{m}$ have been shown to exhibit minimal toxicity to various cell types, such as human promyelocytic leukemia (HL60) and human T-cells (Jurkat). ${ }^{28}$ Our current study also confirmed that shorter MWCNTs ( $\sim 500 \mathrm{~nm})$ exhibited no observable toxicity to macrophages in vitro.

In addition to CNT length, surface functionalization has also been reported to impact toxicity. For example, Li et $\mathrm{al}^{29}$ reported that pulmonary toxicity of covalently functionalized MWCNTs is highly dependent on surface charge associated with sidewall modification. Furthermore, chemical functionalization of MWCNTs was also reported to alleviate the asbestos-like pathogenicity of long $\mathrm{CNTs}^{30}$ and exert no cytotoxicity to primary immune cells (such as T-cells, B-cells, and macrophages). ${ }^{31}$ In addition, Moore et $\mathrm{al}^{8}$ demonstrated that coating with poly(lactide)-poly(ethylene glycol) reduced the toxicity of CNTs both in vitro and in vivo due to the lower degree of aggregation. Recent evidence has also reported the possibility of the degradation of CNTs by cells, such as neutrophils, ${ }^{32}$ microglia, ${ }^{33}$ and macrophages. ${ }^{34-36}$ Overall, the current data suggest that the toxicity of MWCNTs can be at least partly reduced or minimized by improving design strategies of short-length MWCNT with appropriate surface modifications that are feasible for degradation by cells after the delivery of loaded proteins or drugs.

Recent studies showed that macrophages have great functional diversity in various tissues and play roles in development, homeostasis, tissue repair, and immunity ${ }^{37}$ and were also explored to be target cells in the development of nanoparticle-based drug delivery systems for various diseases, including cancer. ${ }^{38,39}$ For example, Zeinali et al ${ }^{40}$ reported that tuberculin purified protein derivative in conjugation with carboxylated single-walled CNTs generated preferentially a type $1 \mathrm{~T}$ helper cytokine response without potential cytotoxic effects. These studies inspired us to investigate the ability of MWCNTs with surface modifications to deliver an antigen to macrophages. In this study, we demonstrated the robust activation of macrophages over time characterized by elevated production of TNF $\alpha$ and IL-6 and increased MHCII expression and the enhanced proliferation of $\mathrm{CD}^{+} \mathrm{T}$-cells following treatment with MWCNT-OVA complex.
Similarly, dendritic cells have also been studied in nanoparticle-based drug delivery systems. For example, de Faria et $\mathrm{al}^{6}$ demonstrated that dendritic cells treated with MWCNT-OVA complex induced a robust proliferative response for both $\mathrm{CD}^{+}$and $\mathrm{CD}^{+} \mathrm{T}$-cells. In addition, the proliferation of T-cells was induced after coculture with dendritic cells treated with polypropylene sulfide nanoparticle-OVA complex ${ }^{41}$ and polystyrene nanospheresOVA complex. ${ }^{42}$ Given the capability of antigen presentation shared by dendritic cells and macrophages, these studies strongly support our study that MWCNTs can be used as a promising delivery vehicle to load the antigen into the APCs to stimulate the immune responses in the development of the next generation of vaccines. Our future direction will further address the ability of carboxylated MWCNTs to deliver the antigen or allergen in animal studies and investigate the toxicity using various methods, as well as the possibility of different surface functionalization to alter the immune response in vivo. In addition, future studies should examine efficient methods to modify the frequency of defect sites on MWCNTs to improve their capability to bind antigen and optimize MWCNT-based drug/antigen delivery systems.

\section{Conclusion}

We demonstrated that carboxylated MWCNTs showed no observable toxicity to BMDMs. Rather, an increase in MWCNT defect density promoted protein binding leading to successful delivery of OVA into macrophages and promoted $\mathrm{CD}^{+} \mathrm{T}$-cell proliferation. Overall, these data suggest that in addition to surface modification such as carboxylation, surface defect density should be considered in the design of novel CNT platforms for vaccine delivery.

\section{Acknowledgment}

This study was supported by the National Institutes of Health (grant R03 ES023036).

\section{Disclosure}

The authors report no conflicts of interests in this study.

\section{References}

1. Butterfield LH. Cancer vaccines. BMJ. 2015;350:h988.

2. Ryan EJ, Daly LM, Mills KH. Immunomodulators and delivery systems for vaccination by mucosal routes. Trends Biotechnol. 2001;19(8): 293-304.

3. Lindblad EB. Aluminium compounds for use in vaccines. Immunol Cell Biol. 2004;82(5):497-505.

4. Smith DM, Simon JK, Baker JR Jr. Applications of nanotechnology for immunology. Nat Rev Immunol. 2013;13(8):592-605.

5. Villa CH, Dao T, Ahearn I, et al. Single-walled carbon nanotubes deliver peptide antigen into dendritic cells and enhance IgG responses to tumorassociated antigens. ACS Nano. 2011;5(7):5300-5311. 
6. de Faria PC, dos Santos LI, Coelho JP, et al. Oxidized multiwalled carbon nanotubes as antigen delivery system to promote superior CD8(+) T cell response and protection against cancer. Nano Lett. 2014;14(9): 5458-5470.

7. Wong BS, Yoong SL, Jagusiak A, et al. Carbon nanotubes for delivery of small molecule drugs. Adv Drug Deliv Rev. 2013;65(15):1964-2015.

8. Moore TL, Pitzer JE, Podila R, et al. Multifunctional polymer-coated carbon nanotubes for safe drug delivery. Part Part Syst Charact. 2013; $30: 8$.

9. Yan L, Zhao F, Li S, Hu Z, Zhao Y. Low-toxic and safe nanomaterials by surface-chemical design, carbon nanotubes, fullerenes, metallofullerenes, and graphenes. Nanoscale. 2011;3(2):362-382.

10. Kostarelos K, Bianco A, Prato M. Promises, facts and challenges for carbon nanotubes in imaging and therapeutics. Nat Nanotechnol. 2009; 4(10):627-633.

11. Fadel TR, Fahmy TM. Immunotherapy applications of carbon nanotubes: from design to safe applications. Trends Biotechnol. 2014;32(4): 198-209.

12. Battigelli A, Menard-Moyon C, Da Ros T, Prato M, Bianco A. Endowing carbon nanotubes with biological and biomedical properties by chemical modifications. Adv Drug Deliv Rev. 2013;65(15):1899-1920.

13. Shannahan JH, Brown JM, Chen R, et al. Comparison of nanotubeprotein corona composition in cell culture media. Small. 2013;9(12): 2171-2181.

14. Chen Y, Mitra S. Fast microwave-assisted purification, functionalization and dispersion of multi-walled carbon nanotubes. J Nanosci Nanotechnol. 2008;8(11):5770-5775.

15. Sengupta B, Gregory WE, Zhu J, et al. Influence of carbon nanomaterial defects on the formation of protein corona. RSC Adv. 2015;5(100): 82395-82402.

16. Gordon S. Alternative activation of macrophages. Nat Rev Immunol. 2003;3(1):23-35.

17. Heister E, Brunner EW, Dieckmann GR, Jurewicz I, Dalton AB. Are carbon nanotubes a natural solution? Applications in biology and medicine. ACS Appl Mater Interfaces. 2013;5(6):1870-1891.

18. De Volder MF, Tawfick SH, Baughman RH, Hart AJ. Carbon nanotubes: present and future commercial applications. Science. 2013;339(6119): 535-539.

19. Saito N, Haniu H, Usui Y, et al. Safe clinical use of carbon nanotubes as innovative biomaterials. Chem Rev. 2014;114(11):6040-6079.

20. Hsieh HS, Wu R, Jafvert CT. Light-independent reactive oxygen species (ROS) formation through electron transfer from carboxylated singlewalled carbon nanotubes in water. Environ Sci Technol. 2014;48(19): 11330-11336.

21. Manke A, Wang L, Rojanasakul Y. Mechanisms of nanoparticle-induced oxidative stress and toxicity. Biomed Res Int. 2013;2013:942916.

22. Wang X, Katwa P, Podila R, et al. Multi-walled carbon nanotube instillation impairs pulmonary function in C57BL/6 mice. Part Fibre Toxicol. 2011;8:24.

23. Urankar RN, Lust RM, Mann E, et al. Expansion of cardiac ischemia/ reperfusion injury after instillation of three forms of multi-walled carbon nanotubes. Part Fibre Toxicol. 2012;9:38.

24. Chen R, Zhang L, Ge C, et al. Subchronic toxicity and cardiovascular responses in spontaneously hypertensive rats after exposure to multiwalled carbon nanotubes by intratracheal instillation. Chem Res Toxicol. 2015;28(3):440-450.
25. Poland CA, Duffin R, Kinloch I, et al. Carbon nanotubes introduced into the abdominal cavity of mice show asbestos-like pathogenicity in a pilot study. Nat Nanotechnol. 2008;3(7):423-428.

26. Ryman-Rasmussen JP, Tewksbury EW, Moss OR, Cesta MF, Wong BA, Bonner JC. Inhaled multiwalled carbon nanotubes potentiate airway fibrosis in murine allergic asthma. Am J Respir Cell Mol Biol. 2009;40(3):349-358.

27. Donaldson K, Aitken R, Tran L, et al. Carbon nanotubes: a review of their properties in relation to pulmonary toxicology and workplace safety. Toxicol Sci. 2006;92(1):5-22.

28. Shi Kam NW, Jessop TC, Wender PA, Dai H. Nanotube molecular transporters: internalization of carbon nanotube-protein conjugates into Mammalian cells. J Am Chem Soc. 2004;126(22):6850-6851.

29. Li R, Wang X, Ji Z, et al. Surface charge and cellular processing of covalently functionalized multiwall carbon nanotubes determine pulmonary toxicity. ACS Nano. 2013;7(3):2352-2368.

30. Ali-Boucetta H, Nunes A, Sainz R, et al. Asbestos-like pathogenicity of long carbon nanotubes alleviated by chemical functionalization. Angew Chem Int Ed Engl. 2013;52(8):2274-2278.

31. Dumortier H, Lacotte S, Pastorin G, et al. Functionalized carbon nanotubes are non-cytotoxic and preserve the functionality of primary immune cells. Nano Lett. 2006;6(7):1522-1528.

32. Kagan VE, Konduru NV, Feng W, et al. Carbon nanotubes degraded by neutrophil myeloperoxidase induce less pulmonary inflammation. Nat Nanotechnol. 2010;5(5):354-359.

33. Nunes A, Bussy C, Gherardini L, et al. In vivo degradation of functionalized carbon nanotubes after stereotactic administration in the brain cortex. Nanomedicine (Lond). 2012;7(10):1485-1494.

34. Elgrabli D, Dachraoui W, Menard-Moyon C, et al. Carbon nanotube degradation in macrophages: live nanoscale monitoring and understanding of biological pathway. ACS Nano. 2015;9(10):10113-10124.

35. Bussy C, Paineau E, Cambedouzou J, et al. Intracellular fate of carbon nanotubes inside murine macrophages: $\mathrm{pH}$-dependent detachment of iron catalyst nanoparticles. Part Fibre Toxicol. 2013;10:24.

36. Kagan VE, Kapralov AA, St Croix CM, et al. Lung macrophages "digest" carbon nanotubes using a superoxide/peroxynitrite oxidative pathway. ACS Nano. 2014;8(6):5610-5621.

37. Wynn TA, Chawla A, Pollard JW. Macrophage biology in development, homeostasis and disease. Nature. 2013;496(7446):445-455.

38. Amoozgar Z, Goldberg MS. Targeting myeloid cells using nanoparticles to improve cancer immunotherapy. Adv Drug Deliv Rev. 2015;91: $38-51$.

39. Jain NK, Mishra V, Mehra NK. Targeted drug delivery to macrophages. Expert Opin Drug Deliv. 2013;10(3):353-367.

40. Zeinali M, Jammalan M, Ardestani SK, Mosaveri N. Immunological and cytotoxicological characterization of tuberculin purified protein derivative (PPD) conjugated to single-walled carbon nanotubes. Immunol Lett. 2009;126(1-2):48-53.

41. Reddy ST, van der Vlies AJ, Simeoni E, et al. Exploiting lymphatic transport and complement activation in nanoparticle vaccines. Nat Biotechnol. 2007;25(10):1159-1164.

42. Wang X, Uto T, Sato K, et al. Potent activation of antigen-specific T cells by antigen-loaded nanospheres. Immunol Lett. 2005;98(1):123-130. 


\section{Supplementary materials}
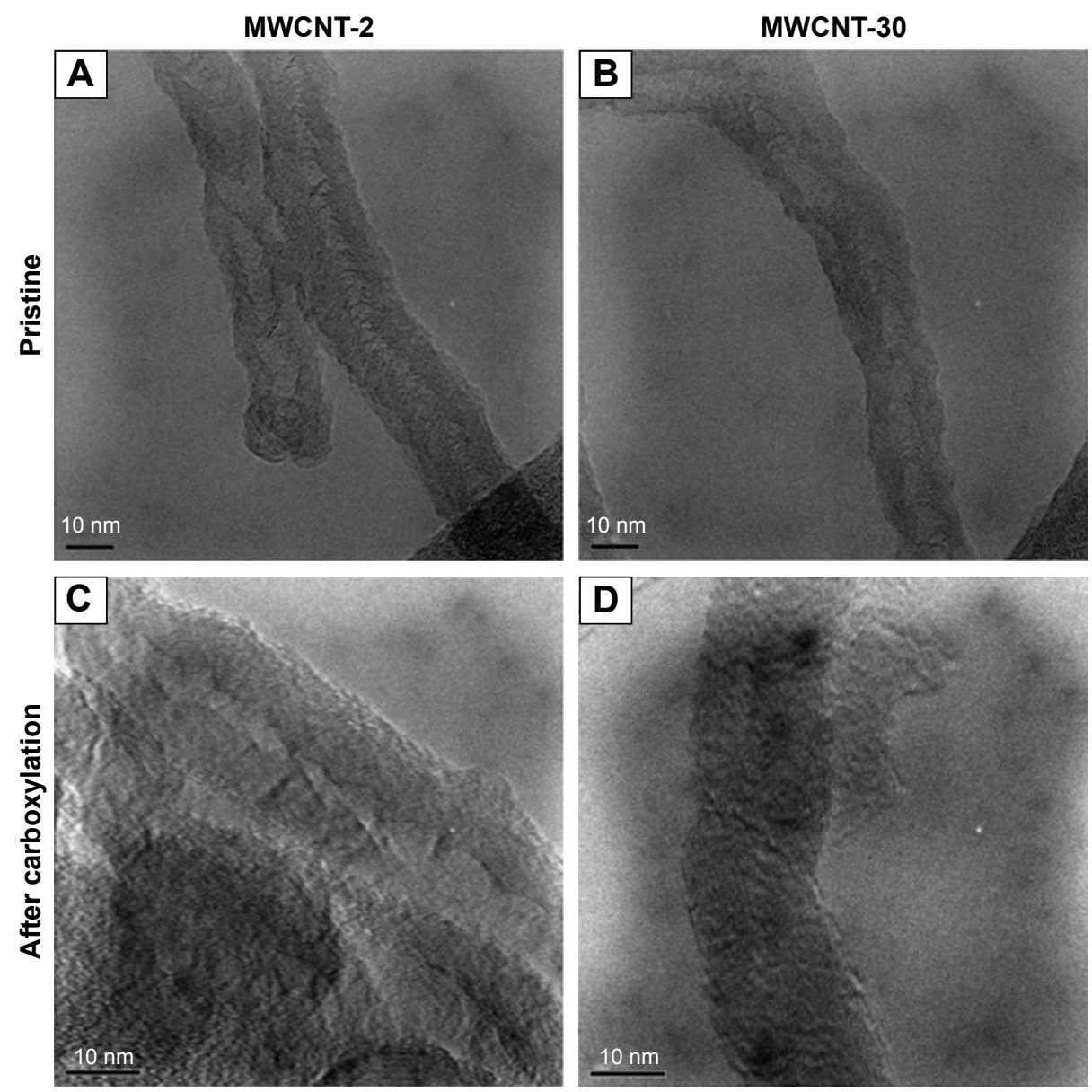

Figure SI TEM images of MWCNTs before and after carboxylation.

Notes: (A) Pristine MWCNT-2, (B) pristine MWCNT-30, (C) carboxylated MWCNT-2, and (D) carboxylated MWCNT-30. After carboxylation, both MWCNT-2 and MWCNT-30 collapsed and became more rugged.

Abbreviations: MWCNT, multiwalled carbon nanotube; TEM, transmission electron microscopy.

Table SI XPS results of MWCNT-2 and MWCNT-30 samples obtained using a Kratos Axis Ultra DLD instrument and spectra were calibrated by C Is at $284.6 \mathrm{eV}$

\begin{tabular}{llllll}
\hline Sample & Peak & Position $(\mathrm{eV})$ & Full width $(\mathrm{eV})$ & Raw area (counts/s) & Conc $($ wt\%) \\
\hline MWCNT-2 & O Is & 531.84 & 3.47 & $4,491.8$ & 7.3 \\
\multirow{2}{*}{ MWCNT-30 } & C Is & 284.40 & 0.78 & $20,284.3$ & 92.7 \\
& O Is & 531.72 & 3.54 & $5,163.3$ & 11.5 \\
\hline
\end{tabular}

Abbreviations: MWCNT, multiwalled carbon nanotube; XPS, X-ray photoelectron spectroscopy. 


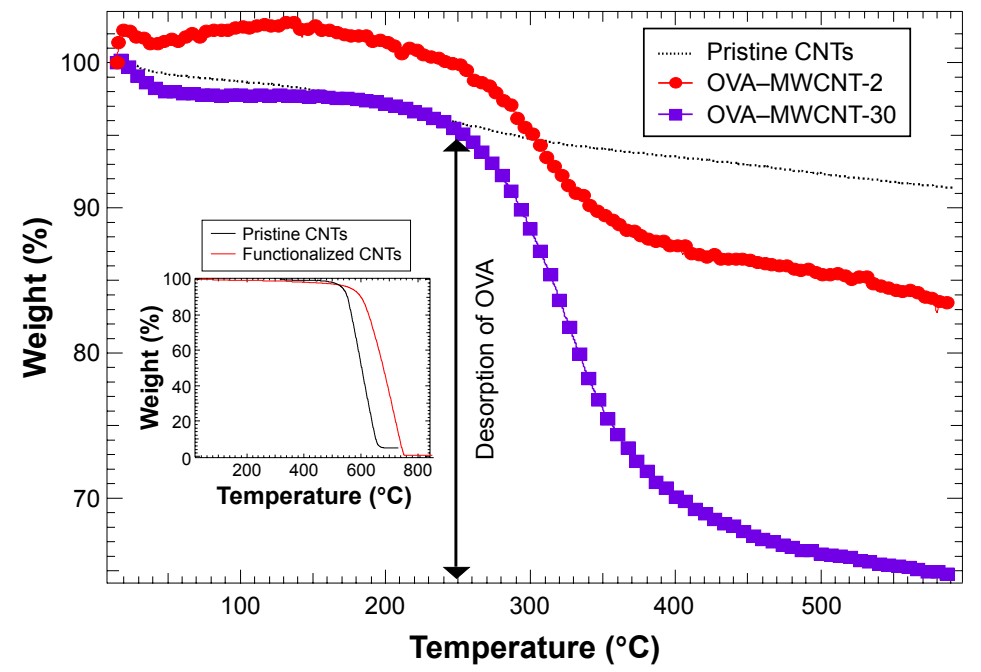

Figure S2 TGA that was carried out in a Perkin Elmer Thermogravimetric Analyzer Pyris I TGA.

Notes: Approximately $40 \%-50 \%$ of the volume of the platinum pan was filled with MWCNTs $\left(\sim 0.1-0.2 \mathrm{~cm}^{3}\right)$. The samples were then heated from $30^{\circ} \mathrm{C}$ up to $800^{\circ} \mathrm{C}$ at a heating rate of $20^{\circ} \mathrm{C} / \mathrm{min}$ in an air atmosphere using an airflow rate of $20 \mathrm{~mL} / \mathrm{min}$. We observed a marked decrease in the weight percent for CNT-OVA complexes with increasing temperature unlike pristine CNTs confirming the presence of OVA. Based on these data, we found the amount of OVA bound to MWCNT-2 and MWCNT-30 was $150 \pm 10 \mu \mathrm{g} / \mathrm{mL}$ and $340 \pm 10 \mu \mathrm{g} / \mathrm{mL}$, respectively. The inset shows the TGA of pristine and functionalized CNTs. While the pristine CNTs showed $\sim 4$ wt\% of Fe catalyst at the end of the reaction; functionalized CNTs (viz, MWCNT-2 and MWCNT-30) had only 0.5 wt\% suggesting the removal of residual catalyst during the microwave reaction. Abbreviations: CNTs, carbon nanotubes; MWCNT, multiwalled carbon nanotube; OVA, ovalbumin; TGA, thermogravimetric analysis.

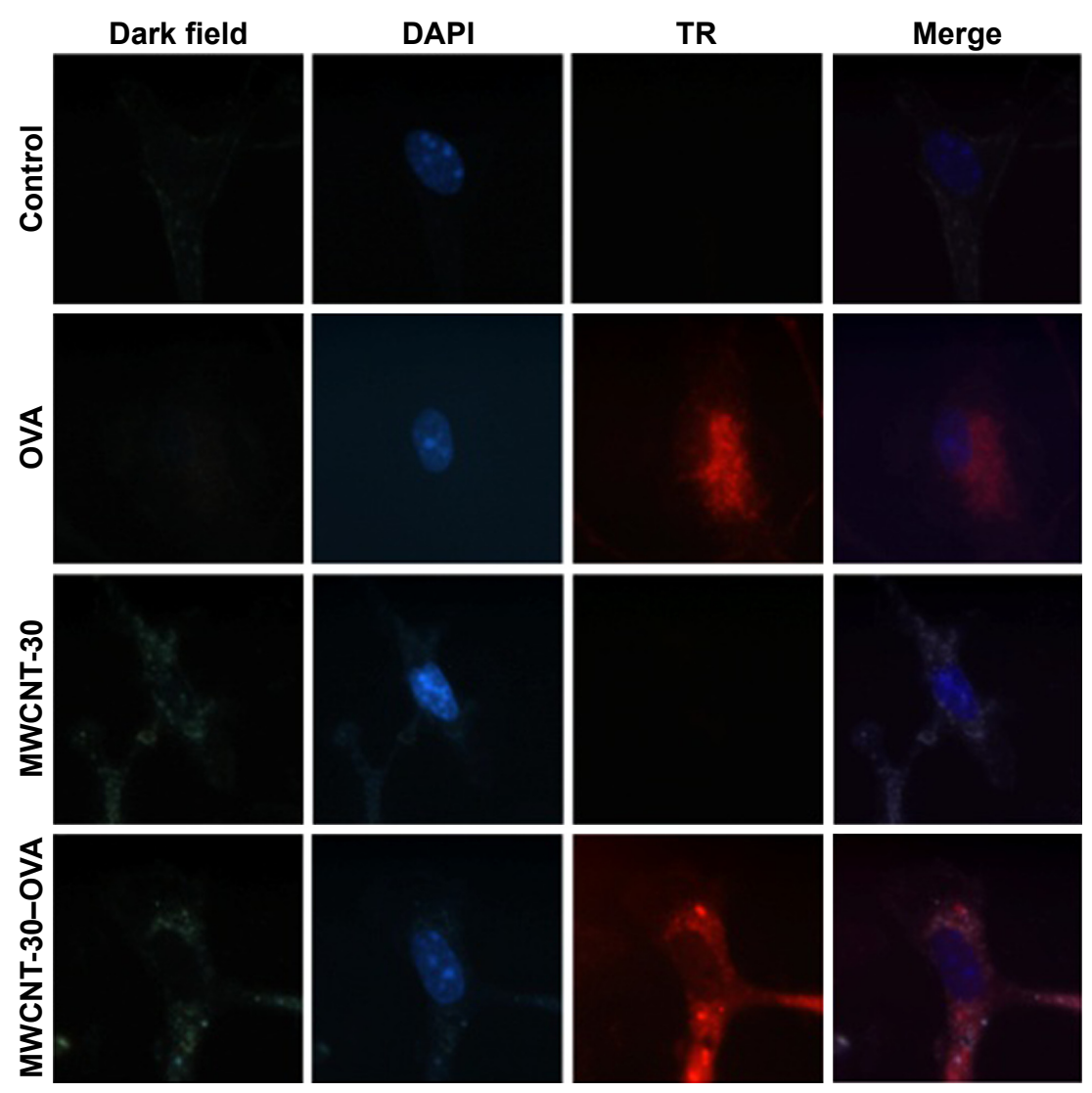

Figure S3 Delivery of fluorescent TR-OVA by MWNCT-30 into BMDMs visualized by dark field and fluorescent microscopy.

Notes: Macrophages treated with MWCNT-30 alone showed no fluorescence, but macrophages treated with MWCNT-TR-OVA complex showed strong fluorescence (magnification: 100X).

Abbreviations: BMDMs, bone-marrow-derived macrophages; DAPI, 4',6-diamidino-2-phenylindole; MWCNT, multiwalled carbon nanotube; OVA, ovalbumin; TR-OVA, Texas Red-conjugated OVA. 
International Journal of Nanomedicine

Dovepress

\section{Publish your work in this journal}

The International Journal of Nanomedicine is an international, peerreviewed journal focusing on the application of nanotechnology in diagnostics, therapeutics, and drug delivery systems throughout the biomedical field. This journal is indexed on PubMed Central, MedLine, CAS, SciSearch ${ }^{\circledR}$, Current Contents ${ }^{\circledR} /$ Clinical Medicine,
Journal Citation Reports/Science Edition, EMBase, Scopus and the Elsevier Bibliographic databases. The manuscript management system is completely online and includes a very quick and fair peer-review system, which is all easy to use. Visit http://www.dovepress.com/ testimonials.php to read real quotes from published authors.

Submit your manuscript here: http://www.dovepress.com/international-journal-of-nanomedicine-journal 